\title{
Thermodynamic Separation of 1-Butene from 2-Butene in Metal-Organic Frameworks with Open Metal Sites
}

\author{
Brandon R. Barnett ${ }^{\mathrm{a}, \mathrm{c}}$, Surya T. Parker ${ }^{\mathrm{b}, \mathrm{c}}$, Maria V. Paley ${ }^{\mathrm{a}}$, Miguel I. Gonzalez ${ }^{\mathrm{a}, \uparrow}$, Naomi Biggins $^{\mathrm{a}, \mathrm{c}}$, Julia Oktawiec ${ }^{\mathrm{a}}$, \\ and Jeffrey R. Long*,a,b,c \\ ${ }^{a}$ Department of Chemistry, and ${ }^{b}$ Department of Chemical \& Biochemical Engineering, University of California, Berkeley, \\ California, 94720, United States \\ ${ }^{\mathrm{c}}$ Materials Sciences Division, Lawrence Berkeley National Laboratory, Berkeley, California 94720, United States
}

\begin{abstract}
Most $\mathrm{C}_{4}$ hydrocarbons are obtained as byproducts of ethylene production or oil refining, and complex and energyintensive separation schemes are required for their isolation. Substantial industrial and academic effort has been expended to develop more cost-effective adsorbent- or membrane-based approaches to purify commodity chemicals such as 1,3-butadiene, isobutene, and 1-butene, but the very similar physical properties of these $\mathrm{C}_{4}$ hydrocarbons makes this a challenging task. Here, we examine the adsorption behavior of 1-butene, cis-2-butene and trans-2-butene in the metal-organic frameworks $\mathrm{M}_{2}(\mathrm{dobdc})(\mathrm{M}=$ $\mathrm{Mn}, \mathrm{Fe}, \mathrm{Co}, \mathrm{Ni}$; dobdc ${ }^{2-}=2,5$-dioxidobenzene-1,4-dicarboxylate) and $\mathrm{M}_{2}$ ( $m$-dobdc) ( $m$-dobdc ${ }^{4-}=4,6$-dioxido-1,3benzenedicarboxylate), which all contain a high density of coordinatively-unsaturated $\mathrm{M}^{2+}$ sites. We find that both $\mathrm{Co}_{2}(m-\mathrm{dobdc})$ and $\mathrm{Ni}_{2}(m$-dobdc $)$ are able to separate 1-butene from the 2-butene isomers, a critical industrial process that relies largely on energetically demanding cryogenic distillation. The origin of 1-butene selectivity is traced to the high charge density retained by the $\mathrm{M}^{2+}$ metal centers exposed within the $\mathrm{M}_{2}(m$-dobdc) structures, which results in a reversal of the cis-2-butene selectivity typically observed at framework open metal sites. Selectivity for 1-butene adsorption under multicomponent conditions is demonstrated for $\mathrm{Ni}_{2}(m$-dobdc $)$ in both the gaseous and liquid phases via breakthrough and batch adsorption experiments.
\end{abstract}

\section{INTRODUCTION}

The separation of hydrocarbon mixtures is carried out on an immense scale in industry, where a heavy reliance on cryogenic distillation results in substantial and costly energy expenditure. ${ }^{1-3}$ Accordingly, there is great interest in incorporating more energy-efficient adsorbent- or membrane-based technologies into existing hydrocarbon separation schemes. ${ }^{4}$ Much of this focus has centered on the separation of $\mathrm{C}_{2}$ or $\mathrm{C}_{3}$ hydrocarbon mixtures, given substantial global demand for ethylene and propylene, ${ }^{5-10}$ while alternative separation schemes for $\mathrm{C}_{4}$ hydrocarbon mixtures have received far less attention. Most $\mathrm{C}_{4}$ hydrocarbons are obtained as byproducts from steam cracking in ethylene plants and refinery fluid catalytic cracking, and their fractionation from complex mixtures is necessary for isolation of individual components. ${ }^{11-13}$ The $\mathrm{C}_{4}$ cut from steam crackers contains significant quantities of 1,3butadiene, which can be isolated using extractive distillation or removed via selective hydrogenation. This produces a mixture of mono-olefin (1-butene, cis-2-butene, trans-2-butene, isobutene) and paraffin ( $n$-butane, isobutane) isomers, known as Raffinate I. Isobutene is most commonly oligomerized or converted to tert-butanol or tert-butyl ethers and then separated, leaving a mixture of the $n$-butenes and $\mathrm{C}_{4}$ paraffins known as Raffinate II. While much of Raffinate II is used as a feedstock for alkylate gasoline production, this mixture is also used to produce high-grade 1-butene, which is in wide demand as a monomer for the production of poly-1-butene, high- density polyethylene, and linear low-density polyethylene. $^{12,14,15}$ These processes require 1-butene purities in excess of $99.5 \%$, and thus its separation from Raffinate II typically requires multiple separation stages. The high-purity separation of 1-butene from the 2-butenes is particularly challenging, and often relies on energy-intensive cryogenic distillation. $^{11}$

Table 1. Relevant physical properties of $\mathrm{C}_{4}$ olefins and paraffins. ${ }^{16,17}$

\begin{tabular}{ccccc}
\hline Compound & $\begin{array}{c}\text { Boiling } \\
\text { Point } \\
(\mathbf{K})\end{array}$ & $\begin{array}{c}\text { Kinetic } \\
\text { Diameter } \\
(\AA \mathbf{\AA})\end{array}$ & $\begin{array}{c}\text { Dipole } \\
\text { Moment } \\
(\mathbf{D})\end{array}$ & $\begin{array}{c}\text { Polarizability } \\
\left(\mathbf{1 0}-\mathbf{2 5} \mathbf{c m}^{-\mathbf{1}}\right)\end{array}$ \\
\hline 1,3-butadiene & 268.62 & 4.31 & 0.00 & 86.4 \\
isobutene & 266.25 & 4.84 & 0.50 & 80 \\
1-butene & 266.92 & 4.46 & $0.36-0.44$ & $79.7-85.2$ \\
cis-2-butene & 276.87 & 4.94 & 0.30 & 82 \\
trans-2-butene & 274.03 & 4.31 & 0.00 & 81.8 \\
$n$-butane & 272.66 & 4.69 & 0.05 & 82.0 \\
isobutane & 261.34 & 5.28 & 0.13 & $81.4-82.9$ \\
\hline
\end{tabular}

Given their similar boiling points and comparable sizes and physical properties (Table 1), the $\mathrm{C}_{4}$ hydrocarbons are 
particularly challenging to separate. In contrast to lighter $\mathrm{C}_{2-3}$ hydrocarbon mixtures, where the components differ in their degree of unsaturation, the presence of olefin and paraffin isomers leads to diverse mixtures of molecules bearing few chemical handles that can be exploited in viable separation schemes. The fact that only 1,3-butadiene, isobutene, and 1butene are currently marketed with standardized product purities underscores this difficulty, ${ }^{16}$ but also points toward the need for novel, low-cost separations to diversify the availability of high-grade $\mathrm{C}_{4}$ hydrocarbons. The Sorbutene process of UOP uses molecular sieves to produce 1-butene in $99.2 \%$ purity from Raffinate II, although the yield suffers somewhat from in situ isomerization. ${ }^{11}$ Various studies have explored the potential of zeolites to effect useful $\mathrm{C}_{4}$ hydrocarbon separations, ${ }^{16,18}$ with particularly notable success in the selective removal of 1,3-butadiene from $\mathrm{C}_{4}$ mixtures. ${ }^{19-21}$ Separation of $n$-butene mixtures has also been studied using several different zeolitic frameworks. ${ }^{16}$ Notably, all-silica RUB-41 was demonstrated to adsorb both cis- and trans-2-butene selectively over 1-butene in liquid-phase adsorption and breakthrough experiments. ${ }^{22}$ Unfortunately, the saturation capacities of this zeolite are quite low ( $\leq 1.0 \mathrm{mmol} / \mathrm{g}$ for the 2-butenes) and the origin of its selectivity is not well understood.

Metal-organic frameworks have only been sparingly studied for $\mathrm{C}_{4}$ hydrocarbon separations. ${ }^{23-32}$ Two recent studies leveraged selectivity based on adsorbate $\operatorname{size}^{23}$ or shape ${ }^{24}$ to separate various $\mathrm{C}_{4}$ components, although the necessarily compact framework pores preclude high capacities. One approach to engender higher capacities is to utilize frameworks containing open metal sites, which can act as strong binding sites for hydrocarbon adsorbates. To our knowledge, the only framework featuring open metal sites that has been investigated for $\mathrm{C}_{4}$ hydrocarbon separations is HKUST-1 $\left(\mathrm{Cu}_{3}(\mathrm{btc})_{2}\right.$, btc $^{3-}=$ benzene-1,3,5-tricarboxylate) ${ }^{26,27}$ The unsaturated $\mathrm{Cu}^{2+}$ sites of this material were shown to be capable of discriminating between the $n$-butenes in liquid-phase multicomponent adsorption experiments, albeit with modest selectivities. ${ }^{26}$ The relative adsorption strengths of cis-2-butene $>1$-butene $>$ trans-2-butene found for HKUST-1 mirror those seen in alkali cation-substituted faujasite, ${ }^{33,34}$ where butene adsorption occurs at exposed $\mathrm{M}^{+}$sites. In contrast, a computational study of butene adsorption in $\mathrm{Fe}_{2}$ (dobdc) $\left(\right.$ dobdc $^{2-}=2,5-$ dioxidobenzene-1,4-dicarboxylate; Fe-MOF-74) ${ }^{35}$ predicted preferential adsorption of 1-butene over both 2-butenes at the open $\mathrm{Fe}^{2+}$ sites. $^{36}$ This ordering of adsorption strengths is desirable, as it could enable a single-step purification sequence for 1-butene from Raffinate II feeds, and more broadly this result suggests that unsaturated transition metal cations may be capable of selective 1-butene adsorption.

The high density of open metal sites within the $\mathrm{M}_{2}$ (dobdc) $(\mathrm{M}=\mathrm{Mg}, \mathrm{Mn}, \mathrm{Fe}, \mathrm{Co}, \mathrm{Ni}, \mathrm{Cu}, \mathrm{Zn}$ ) family of frameworks has previously been shown to endow these materials with high capacities for light hydrocarbons, ${ }^{37-42}$ and preferential adsorption of unsaturated hydrocarbons at these metal sites leads to excellent performance in ethylene/ethane and propylene/propane separations. ${ }^{37-39,42}$ Notably, the isomeric series of frameworks $\mathrm{M}_{2}(m$-dobdc) $(\mathrm{M}=\mathrm{Mg}, \mathrm{Mn}, \mathrm{Fe}, \mathrm{Co}, \mathrm{Ni} ; m$ dobdc $^{4-}=4,6$-dioxido-1,3-benzenedicarboxylate $)^{43}$ was found to exhibit superior performance in the separation of eth- ylene/ethane and propylene/propane mixtures, a result of increased open metal site charge density afforded by the $m$ dobdc $^{4-}$ ligand. ${ }^{44}$ Finally, $\mathrm{Co}_{2}(\mathrm{dobdc})$ and $\mathrm{Co}_{2}(m$-dobdc $)$ frameworks have been shown to separate mixtures of xylene isomers as a result of unique synergistic interactions between adjacent metal centers in each material. ${ }^{45}$ All together, these results highlight the potential of these two framework families to effect the separations mixtures of higher olefin isomers through a combination of interactions involving preferential adsorption of the $\mathrm{C}=\mathrm{C}$ double bond at the open $\mathrm{M}^{2+}$ sites and steric conflicts with the pore walls that can facilitate alkane isomer separations. ${ }^{46}$ Here, we explore the ability of $\mathrm{M}_{2}$ (dobdc) and $\mathrm{M}_{2}(m$-dobdc $)(\mathrm{M}=\mathrm{Mn}, \mathrm{Fe}, \mathrm{Co}, \mathrm{Ni})$ to separate mixtures of 1-butene, cis-2-butene, and trans-2-butene. Crystallographic studies provide insight into the metal-butene interactions, enabling rationalization of the observed adsorption profiles in both classes of adsorbents. In particular, $\mathrm{Co}_{2}(\mathrm{~m}$ dobdc) and $\mathrm{Ni}_{2}(m$-dobdc) are found to exhibit a remarkable selectivity for adsorption of 1-butene over the 2-butenes, and the observed selectivity trends allow for correlation of separation performance with the electronic character of the unsaturated metal site. Breakthrough experiments and liquid-phase batch adsorption verify that this selectivity is retained under multicomponent conditions, enabling the separation of valuable 1-butene from mixtures with the internal olefins.

\section{GAS ADSORPTION ISOTHERMS}

Single-component gas adsorption isotherms were collected at $328 \mathrm{~K}$ to investigate the ability of the $\mathrm{M}_{2}$ (dobdc) and $\mathrm{M}_{2}(m$-dobdc $)(\mathrm{M}=\mathrm{Mn}, \mathrm{Fe}, \mathrm{Co}, \mathrm{Ni})$ frameworks to discriminate between the $n$-butene isomers (Figure 1). As previously observed for ethylene and propylene adsorption in these materials, ${ }^{39,44}$ the isotherms display steep uptake at low pressures and approach saturation at loadings corresponding to one olefin per metal site (approximately $6.3 \mathrm{mmol} / \mathrm{g}$ ). A comparison of the adsorption isotherms within each family of frameworks revealed that, overall, trans-2-butene adsorbs more weakly than 1-butene and cis-2-butene, as indicated by the higher onset adsorption pressure of trans-2-butene adsorption. This finding is consistent with other studies of butene adsorption at framework open metal sites. ${ }^{26,33,34}$ In particular, the trans arrangement of the methyl groups results in steric hindrance to metal coordination, as there is no possible coordination geometry that can orient both methyl groups away from the metal center. While this effect is somewhat mitigated due to the long $\mathrm{M}-\mathrm{C}$ distances observed for all butene isomers studied here (see below), the absence of a permanent dipole moment in trans-2-butene further attenuates its interaction with the positively charged metal centers.

In general, the uptake of each isomer at low pressures is higher in the $\mathrm{M}_{2}\left(m\right.$-dobdc) series than in $\mathrm{M}_{2}$ (dobdc). This effect is most pronounced for 1-butene, which has very similar low-pressure uptake to cis-2-butene in all of the studied $\mathrm{M}_{2}$ (dobdc) materials (Figure 1). For example, $\mathrm{Ni}_{2}(m$-dobdc) achieves a 1-butene loading of $1.0 \mathrm{mmol} / \mathrm{g}\left(\sim 0.15 \mathrm{olefin} / \mathrm{M}^{2+}\right)$ at $0.10 \mathrm{mbar}$, 

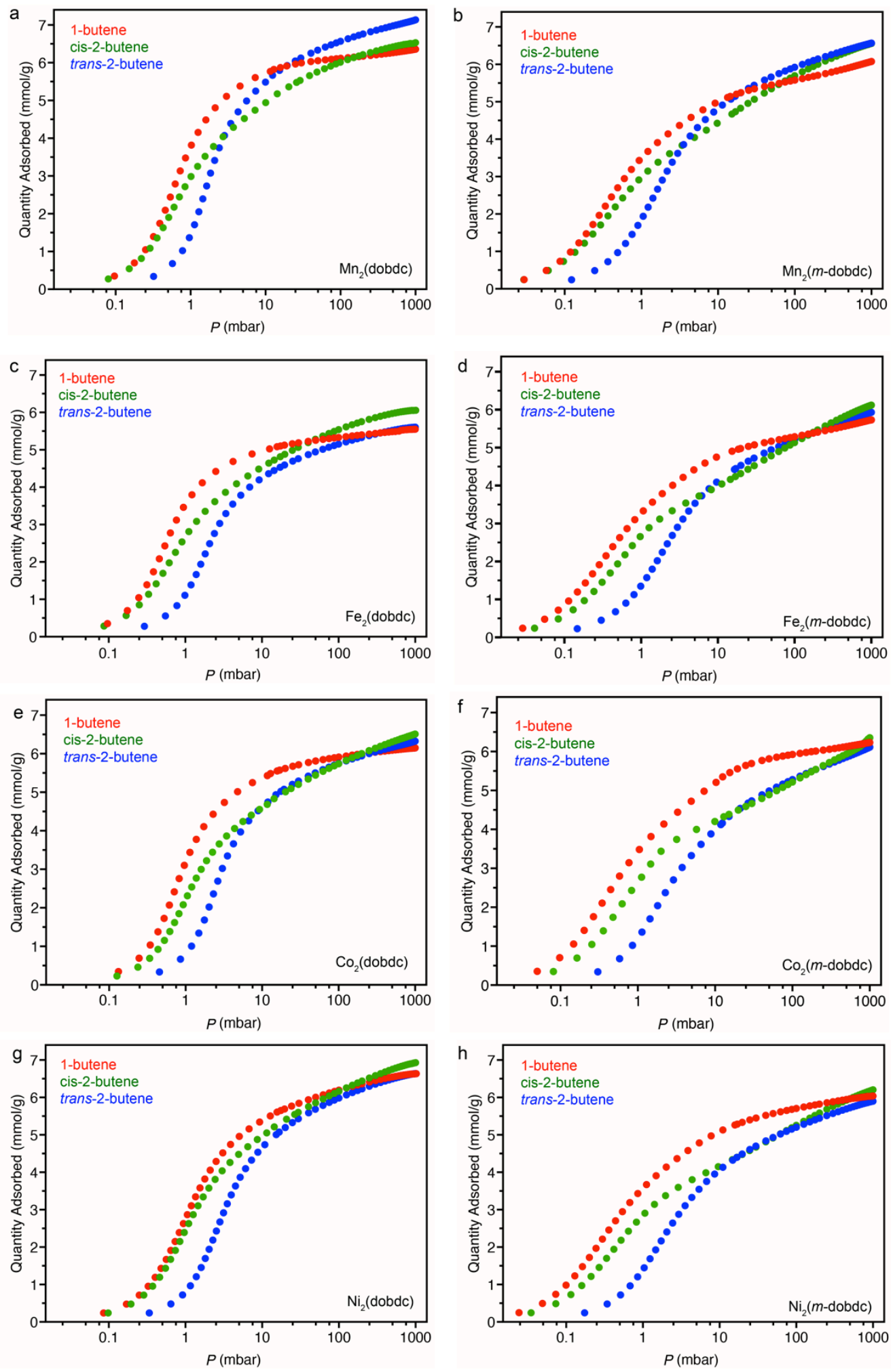

Figure 1. Single-component 1-butene, cis-2-butene, and trans-2-butene adsorption isotherms for $\mathrm{M}_{2}(\mathrm{dobdc})(\mathrm{left})$ and $\mathrm{M}_{2}(m$-dobdc) (right) at $328 \mathrm{~K}$.

whereas a pressure of $0.34 \mathrm{mbar}$ is required to achieve the same loading in $\mathrm{Ni}_{2}$ (dobdc) (Table 2). In contrast, the pressures required to reach the same loading of cis-2-butene in $\mathrm{Ni}_{2}$ (dobdc) and $\mathrm{Ni}_{2}(m$-dobdc) differ by a smaller factor of 2.4 . While all materials display 1-butene uptakes that exceed those of cis-2-butene at intermediate pressures, this is likely due in part to more significant adsorbate-adsorbate interactions in the case of 1-butene (see below). Only $\mathrm{Fe}_{2}\left(m\right.$-dobdc), $\mathrm{Co}_{2}(m-$ dobdc), and $\mathrm{Ni}_{2}(m$-dobdc) show higher 1-butene uptakes at even the lowest pressure points, where uptake correlates the 
most strongly with metal-olefin adsorption strength. Accordingly, it appears as though the $\mathrm{M}_{2}(m$-dobdc) frameworks are uniquely primed to achieve discrimination of 1-butene and cis2-butene. Only the soft $\mathrm{Mn}^{2+}$ open metal sites in $\mathrm{Mn}_{2}(m$ dobdc) display poor performance in this regard, suggesting that harder and more charge-dense metal centers represent better candidates for achieving 1-butene selectivity. Indeed, a prior computational study predicted that 1-butene should adsorb preferentially over cis-2-butene at compact, highlycharged metal centers, while softer cations should interact more strongly with cis-2-butene. ${ }^{34}$ Comparing the two families of frameworks, it is the increased charge density ${ }^{43}$ at the open metal sites in $\mathrm{M}_{2}\left(m\right.$-dobdc) versus $\mathrm{M}_{2}($ dobdc $)$ that is likely a dominant factor leading to the greater selectivity for 1-butene over cis-2-butene. It is unlikely that charge transfer, such as occurs in $\pi$-backbonding, ${ }^{36}$ plays a significant role, given the high-spin electronic configurations of the metal centers and long $\mathrm{M}-\mathrm{C}_{\text {olefin }}$ distances evident from crystal structure determinations (see below).

Table 2. Pressures (mbar) at which each framework reaches a loading of $1.00 \mathrm{mmol} / \mathrm{g}$ for the indicated adsorbate at $328 \mathrm{~K}^{\mathrm{a}}$

\begin{tabular}{cccc}
\hline & 1-butene & cis-2-butene & trans-2-butene \\
\hline $\mathrm{Mn}_{2}($ dobdc $)$ & 0.24 & 0.27 & 0.77 \\
$\mathrm{Mn}_{2}(m$-dobdc $)$ & 0.12 & 0.14 & 0.51 \\
$\mathrm{Fe}_{2}$ (dobdc) & 0.24 & 0.29 & 0.91 \\
$\mathrm{Fe}_{2}(m$-dobdc $)$ & 0.12 & 0.19 & 0.71 \\
$\mathrm{Co}_{2}$ (dobdc $)$ & 0.34 & 0.46 & 1.17 \\
$\mathrm{Co}_{2}(m$-dobdc $)$ & 0.14 & 0.24 & 0.83 \\
$\mathrm{Ni}_{2}($ dobdc $)$ & 0.34 & 0.39 & 1.19 \\
$\mathrm{Ni}_{2}(m$-dobdc $)$ & 0.10 & 0.16 & 0.70 \\
\hline
\end{tabular}

${ }^{\mathrm{a}}$ Isosteric pressures were obtained from Langmuir-Freundlich fits to the $328 \mathrm{~K}$ isotherm data (see Tables S1-8 for fitting parameters).

Using the Clausius-Clapeyron relationship, differential enthalpies of adsorption were calculated from LangmuirFreundlich fits of the single-component isotherm data collected at 308, 318, and $328 \mathrm{~K}$ (Figures S2-S10). The differential enthalpy values calculated for all three isomers on each adsorbent are approximately -50 to $-60 \mathrm{~kJ} / \mathrm{mol}$ at low coverage, and in all cases are seen to become larger with increasing loadings. This trend is likely the result of attractive interactions between adsorbed butene molecules, which should become more prominent at higher coverages. ${ }^{47}$ The differential enthalpy values for 1-butene generally show the largest degree of increase at higher loadings, with maximum values being $\sim 20-25 \mathrm{~kJ} / \mathrm{mol}$ larger in magnitude than at zero coverage. The presence of more significant adsorbate-adsorbate interactions for 1-butene is not surprising, as its ethyl group can extend further into the framework one-dimensional channels than the methyl groups of the 2-butenes. The more modest loading dependencies for the 2-butene isomers are similar to those previously characterized for adsorption of propylene, which features a single methyl substituent on the olefin, in $\mathrm{M}_{2}(\mathrm{~m}$ dobdc). ${ }^{44}$ We note that the significant adsorbate-adsorbate interactions make these isotherms challenging to properly model. In nearly all cases, the use of three distinct sites in the
Langmuir-Freundlich equation was necessary to obtain fits of good quality. Owing to this difficulty, there are some modest errors associated with the calculated differential enthalpies. Accordingly, it is difficult to make meaningful comparisons between the enthalpy magnitudes for different frameworks or adsorbates, especially when these values are anticipated to differ from each other by only a few $\mathrm{kJ} / \mathrm{mol}$ at low coverage. ${ }^{34}$

\section{STRUCTURAL CHARACTERIZATION OF BUTENE ADSORPTION}

Crystal structure determinations for $\mathrm{Co}_{2}(\mathrm{dobdc})$ and $\mathrm{Co}_{2}$ (m-dobdc) loaded with each $n$-butene isomer were first carried out to facilitate comparison of the adsorption profiles observed for both framework families. The Co variants of each material were chosen given the availability of suitable single crystals of $\mathrm{Co}_{2}$ (dobdc), which allows for the determination of precise structural parameters. Single-crystal X-ray diffraction data were collected at $100 \mathrm{~K}$ on butene-loaded single crystals of $\mathrm{Co}_{2}$ (dobdc). Unlike most molecular transition metal-olefin complexes, in which the olefin binds in symmetrical fashion with its $\pi$-cloud pointing toward an empty metal valence orbital, ${ }^{48}$ the $\mathrm{Co}_{2}(\mathrm{dobdc})\left(\mathrm{C}_{4} \mathrm{H}_{8}\right)_{x}$ structures exhibit hydrocarbon binding geometries that reflect both a largely electrostatic interaction with $\mathrm{Co}^{2+}$ and the effects of the surrounding pore environment (Figure 2). Consistent with its preferential adsorption determined from single-component isotherms, $\mathrm{Co}_{2}$ (dobdc)(1-butene $)_{1.59}$ exhibits the shortest average $\mathrm{Co}-\mathrm{C}$ distance of all the butene loaded samples (2.789(4) $\AA$ ). In both $\mathrm{Co}_{2}(\text { dobdc)(1-butene })_{1.59}$ and $\mathrm{Co}_{2}($ dobdc $)(\text { trans-2-butene })_{1.48}$, the olefins are bound to $\mathrm{Co}^{2+}$ in an asymmetric fashion, although the average $\mathrm{Co}-\mathrm{C}$ bond length in $\mathrm{Co}_{2}$ (dobdc)(trans-2butene $)_{1.48}$ is much larger at 2.992(9) $\AA$. While coordination of the $\mathrm{C}=\mathrm{C}$ double bond in $\mathrm{Co}_{2}($ dobdc $)(\text { cis-2-butene })_{1.58}$ is rather symmetric, with a mean $\mathrm{Co}-\mathrm{C}$ separation of $2.888(4) \AA$, the olefinic $\mathrm{C}-\mathrm{H}$ bonds are canted downward and situated directly over two ligating $\mathrm{O}$ atoms. Thus, while the presence of $\mathrm{H} \cdots \mathrm{O}$ interactions may be a contributor to the olefin binding energy, this geometry also orients the dipole moment of cis-2-butene toward the charged $\mathrm{Co}^{2+}$ center, further enhancing the framework-adsorbate interaction. In general, the butene alkyl groups point outward into the framework pores, allowing for increased dispersion interactions between adsorbed butene molecules. Indeed, examination of the extended lattice for each adsorbed species reveals close contacts between alkyl groups both within the $a b$ plane and extending down the pores in the $c$ direction (Figures 2b-c, S11, and S12).

Crystal structures of $\mathrm{Co}_{2}(m-$ dobdc $)$ loaded with 1-butene and cis-2-butene were obtained through Rietveld refinement of synchrotron powder X-ray diffraction data. In a fashion similar to the binding of cis-2-butene in $\mathrm{Co}_{2}(\mathrm{dobdc})$, the structures of both $\mathrm{Co}_{2}(m \text {-dobdc)(1-butene })_{1.64}$, and $\mathrm{Co}_{2}(m$-dobdc $)(\mathrm{cis}-2-$ butene $)_{2.88}$ show the olefinic $\mathrm{C}-\mathrm{H}$ bonds canted downward toward the coordination sphere of cobalt, placing the $\mathrm{H}$ atoms in close proximity to the ligating $\mathrm{O}$ centers (Figure 3 ). In both structures, the $\mathrm{Co}-\mathrm{C}$ distances are slightly elongated compared to those observed for $\mathrm{Co}_{2}$ (dobdc), with mean values of 2.92(4) $\AA$ for 1-butene and 3.02(8) $\AA$ for cis-2-butene. These orientations likely serve to optimize olefin/framework electrostatic interactions, while also allowing for dispersion interactions between adjacent adsorbates. It should be noted that the occupation of a secondary adsorption site near the center of the pore was also located for 

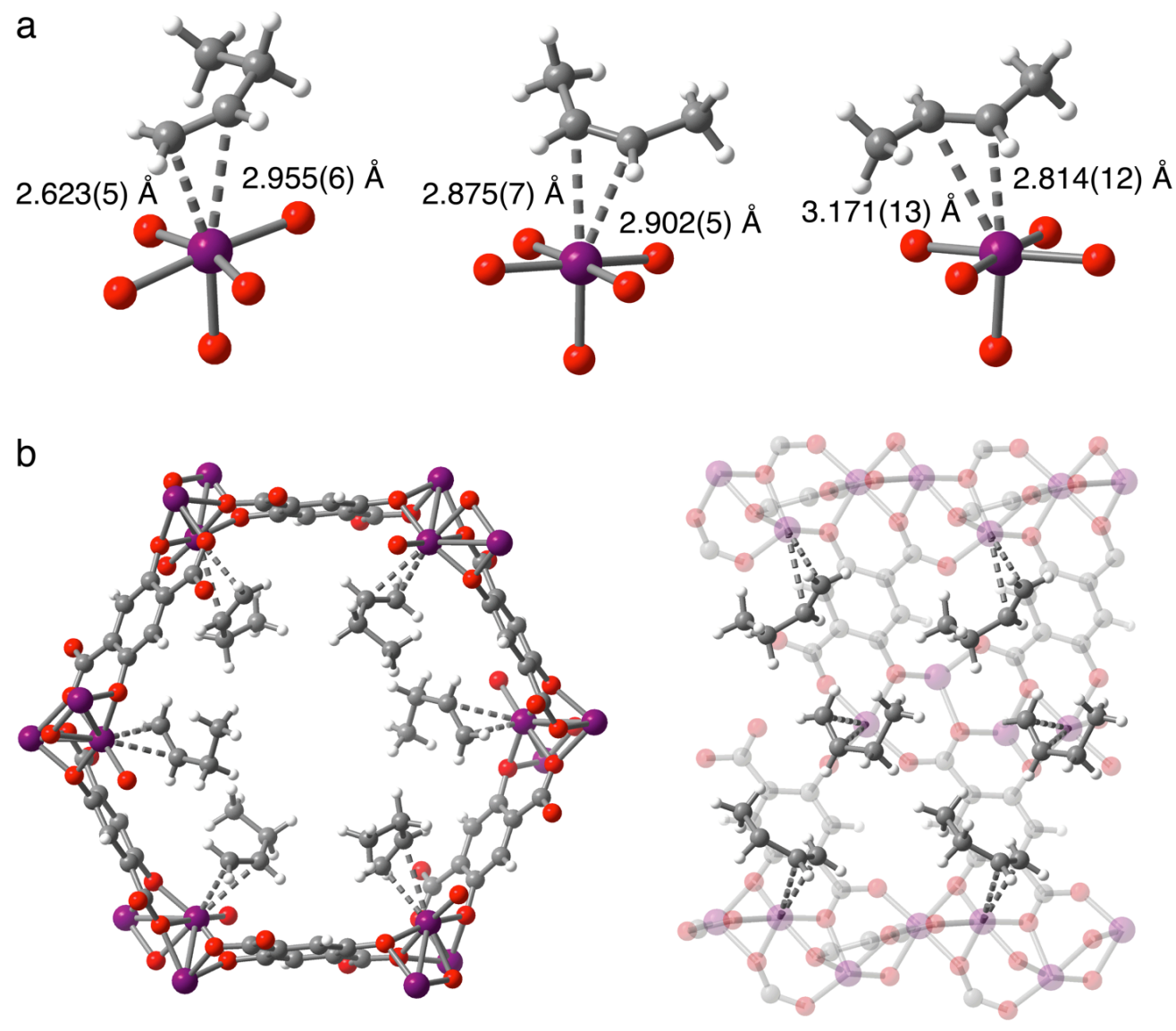

Figure 2. a) Views of the primary coordination spheres in $\mathrm{Co}_{2}(\mathrm{dobdc})(1-\mathrm{butene})_{1.59}, \mathrm{Co}_{2}(\mathrm{dobdc})(\text { cis-2-butene })_{1.58}$, and $\mathrm{Co}_{2}($ dobdc $)($ trans -2 butene $)_{1.48}$ as determined by single crystal X-ray diffraction. b) Views of the structure of $\mathrm{Co}_{2}(\text { dobdc)(1-butene })_{2.0}$ as viewed in the crystallographic $a b$ plane (left) and along the one-dimensional pores (right), showing the proximity of adsorbed 1-butene molecules. Purple, red, grey, and white spheres represent $\mathrm{Co}, \mathrm{O}, \mathrm{C}$, and $\mathrm{H}$ atoms, respectively.

cis-2-butene (Figure S13). However, the adsorbates at this site are disordered across a crystallographic mirror plane, and we were only able to confidently identify the positions of the $\mathrm{sp}^{2}$ carbon atoms. We also collected powder X-ray diffraction data for a sample of $\mathrm{Co}_{2}(m$-dobdc) loaded with trans-2-butene, although significant disorder of the metal-bound olefin has precluded a satisfactory structural solution.

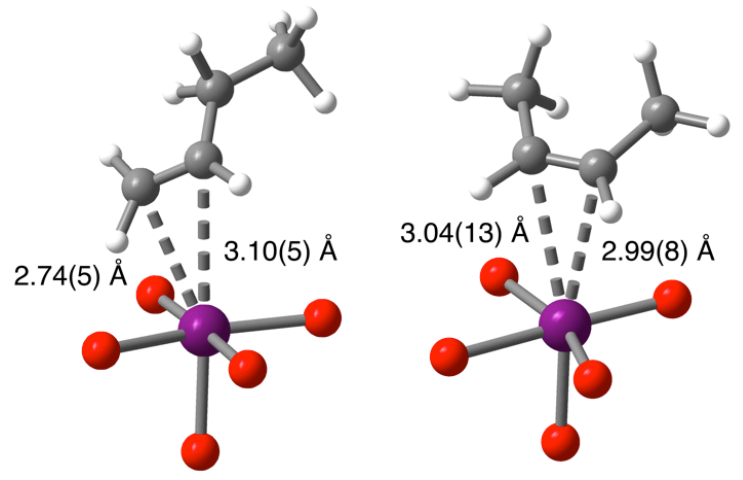

Figure 3. Views of the primary coordination spheres in $\mathrm{Co}_{2}$ (m-dobdc)(1-butene) $)_{1.64}$ and $\mathrm{Co}_{2}(m \text {-dobdc)(cis-2-butene })_{2.88}$. Purple, red, grey, and white spheres represent $\mathrm{Co}, \mathrm{O}, \mathrm{C}$, and $\mathrm{H}$ atoms, respectively.

\section{ADSORPTION SELECTIVITIES}

We used ideal adsorbed solution theory (IAST) to calculate multicomponent equilibrium selectivities for these $\mathrm{C}_{4}$ hydrocarbons in $\mathrm{M}_{2}\left(m\right.$-dobdc) and $\mathrm{M}_{2}$ (dobdc). ${ }^{49,50}$ It is important to note that the adsorbate-adsorbate interactions implicated in our differential adsorption enthalpy and crystallographic data limit the utility of IAST as a method for predicting selectivities. Indeed, this model rigorously assumes that all adsorption events are independent of one another, a point that is unfortunately often overlooked or ignored in the literature. ${ }^{5}$ Although an individual binding site may show selective adsorption of one component in a mixture, dispersion interactions between adsorbed species will not necessarily exhibit the same discriminatory nature. Because IAST exclusively relies on single-component isotherm data, it does not account for potential interactions between different adsorbate molecules. Accordingly, while we have included IAST calculations here to facilitate comparisons with other adsorbents, we note that these values should be viewed as imperfect approximations for the thermodynamic selectivities attainable under multicomponent conditions. 

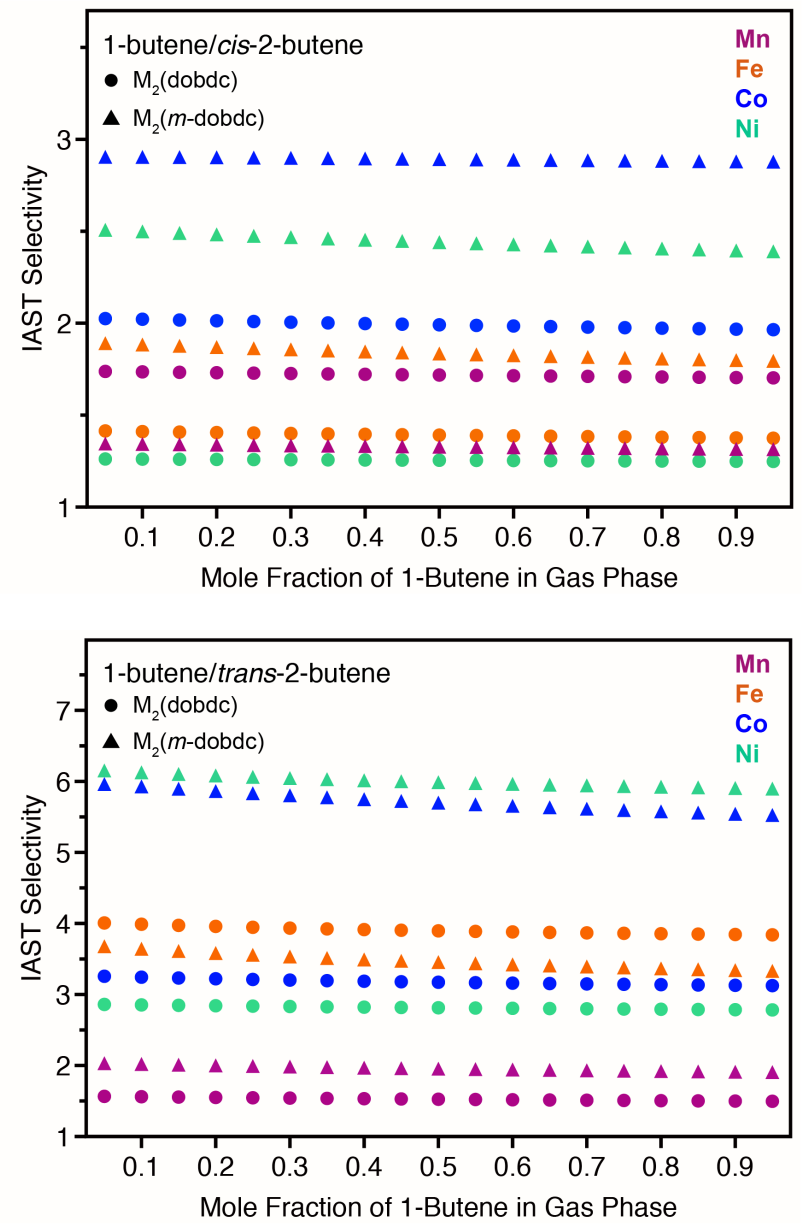

Figure 4. Two-component IAST selectivities obtained at $328 \mathrm{~K}$ for mixtures of 1-butene/cis-2-butene (a) and 1-butene/trans-2butene (b). For $\mathrm{Mn}, \mathrm{Fe}$, and Ni frameworks, the total pressure of each mixture was 1 bar. For $\mathrm{Co}_{2}(m$-dobdc $)$ and $\mathrm{Co}_{2}(\mathrm{dobdc})$, the 1butene/cis-2-butene selectivities were calculated at total pressures of 0.6 and 0.5 bar, respectively, as these are the maximum pressures to which the cis-2-butene isotherms for these frameworks were fit with the Langmuir-Freundlich model (see the Supporting Information).

Selectivity values calculated using IAST for twocomponent 1-butene/cis-2-butene and 1-butene/trans-2-butene mixtures are shown in Figure 4. For all $\mathrm{M}_{2}$ (dobdc) frameworks as well as $\mathrm{Mn}_{2}(m$-dobdc $)$ and $\mathrm{Fe}_{2}(m$-dobdc), the 1butene/cis-2-butene selectivities are less than or equal to 2.0, while the selectivities for $\mathrm{Co}_{2}(m$-dobdc $)$ and $\mathrm{Ni}_{2}(m$-dobdc $)$ are slightly larger at 2.9 and 2.4 , respectively. As discussed above, the superior selectivities for these two frameworks can be traced to the high affinities of their open $\mathrm{Co}^{2+}$ and $\mathrm{Ni}^{2+}$ sites for 1-butene. As a result, $\mathrm{Co}_{2}(m$-dobdc $)$ and $\mathrm{Ni}_{2}(m$-dobdc $)$ also show the largest 1-butene/trans-2-butene selectivities among the materials studied here (5.7 and 6.0, respectively). These values are quite large for an equilibrium process where each olefin has unimpeded access to the unsaturated metal, and demonstrate the potential of charge-dense open metal sites for discriminating between components that share very similar physical properties.
The extremely challenging separation of cis-2-butene and trans-2-butene is usually neglected in industry, since the two isomers behave identically in most reactions of interest. ${ }^{11,16}$ However, economical separation schemes could potentially open up new opportunities for access to purified supplies of these isomers. The two-component selectivity values measured here cis-2-butene/trans-2-butene range from 1.5-2.7 (Figure S1). Unlike the two-component selectivities involving 1-butene, no obvious trends exist between the metal center, framework family, and cis-2-butene/trans-2-butene selectivities. We note that these selectivity values are similar to that measured for the same mixture in HKUST-1 (1.9), ${ }^{26}$ which contains open $\mathrm{Cu}^{2+}$ sites as part of its $\mathrm{Cu}_{2}(\mathrm{COO})_{4}$ paddlewheel motifs. However, the square pyramidal $\mathrm{Cu}^{2+}$ sites in HKUST-1 are unlikely to engage in particularly strong interactions with the olefin adsorbates compared to the frameworks studied in this work. ${ }^{40,51}$ Thus, the thermodynamic selectivity for cis-2butene versus trans-2-butene, while possibly a general feature of metal-organic frameworks with open metal sites, appears less sensitive to the polarizing power of the metal cation compared to the selectivity of 1-butene over the 2-butenes.

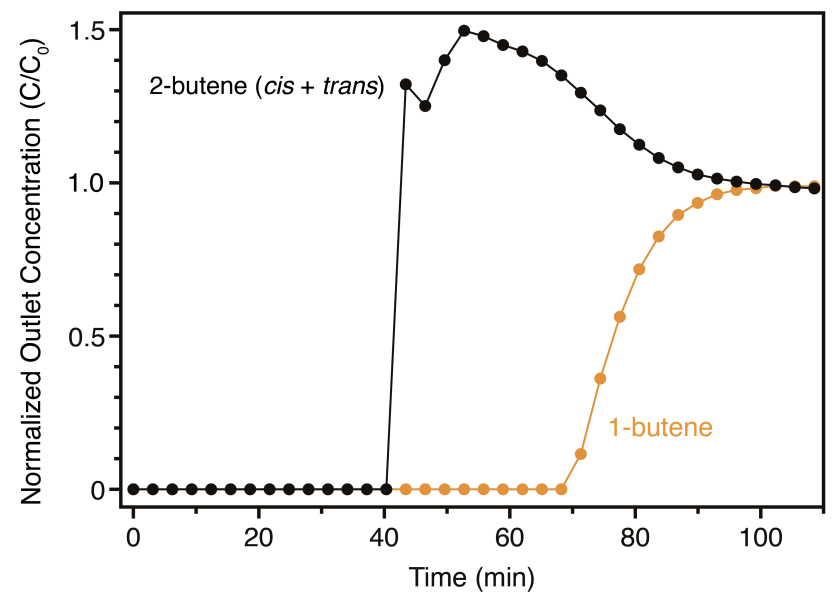

Figure 5. Multicomponent vapor-phase breakthrough data obtained at $328 \mathrm{~K}$ using $\mathrm{Ni}_{2}(m$-dobdc $)$ and an equimolar feed of 1butene/cis-2-butene/trans-2-butene.

\section{MULTICOMPONENT COLUMN BREAKTHROUGH AND BATCH ADSORPTION EXPERIMENTS}

Column breakthrough experiments were carried out using $\mathrm{Ni}_{2}(m$-dobdc) to assess the separation performance attainable under multicomponent conditions more accurately. In these experiments, a pre-mixed gaseous mixture of $n$-butene isomers (1:1:1 ratio diluted in helium) was passed through a column packed with pelletized metal-organic framework and heated to $328 \mathrm{~K}$, and the eluent was analyzed by GC-FID. Given the inability of our gas chromatograph to achieve complete resolution of cis- and trans-2-butene, these isomers were analyzed and integrated together to enable calculation of precise selectivity values for 1-butene over the less desirable internal olefins. Consistent with the ordering of low-pressure butene uptake determined from the single-component isotherm data, the 2-butenes break through the adsorption bed first (Figure 5). The sharp profile of the 2-butene breakthrough curve suggests that this event is an equilibrium rather than a diffusion-limited 
process. ${ }^{52}$ It should be noted that the bifurcation in this curve at $\sim 47 \mathrm{~min}$ is due to slightly different breakthrough times for the cis and trans isomers. The initial elution corresponds to breakthrough of cis-2-butene, a surprising finding given the weaker adsorption of trans-2-butene seen in the singlecomponent isotherm data. However, this multicomponent selectivity ordering is consistent with that seen in the batch liquid adsorption experiments discussed below, and suggests that multicomponent conditions result in an inversion of cis-2butene/trans-2-butene selectivity. Once the adsorbent bed approaches saturation, 1-butene begins to elute, with the outlet concentrations for each isomer promptly returning to those in the feed gas. Integration of the breakthrough curves yields adsorption capacities of 2.58 and $1.87 \mathrm{mmol} / \mathrm{g}$ for 1 -butene and combined 2-butenes, respectively. These capacities equate to a 1-butene selectivity of 2.8. Assuming a 1-butene/2butenes molar feed ratio of 1.4 , representative of steam cracker-derived Raffinate II, ${ }^{12}$ passage through four consecutive adsorption beds would yield 1-butene in 99\% purity. Importantly, such a purification scheme would obviate the final distillation steps required for 1-butene isolation using the UOP Sorbutene process and the competing OlefinSiv procedure from Union Carbide. ${ }^{11}$ In tandem with the high capacity of $\mathrm{Ni}_{2}(m$-dobdc) for 1-butene, the breakthrough performance suggests that this framework is a promising material for further development of alternative $\mathrm{C}_{4}$ olefin separation schemes.

Table 3. Comparison of selectivities calculated for adsorption in $\mathrm{Ni}_{2}(m$-dobdc).

\begin{tabular}{lccc}
\hline & $\begin{array}{c}\text { 1-butene/ } \\
\text { cis-2-butene }\end{array}$ & $\begin{array}{c}\text { 1-butene/ } \\
\text { trans-2-butene }\end{array}$ & $\begin{array}{c}\text { 1-butene/ } \\
\text { 2-butenes }\end{array}$ \\
\hline $\begin{array}{c}\text { IAST }^{\mathrm{a}} \\
\text { Breakthrough } \\
\text { Liquid }\end{array}$ & 2.4 & 6.0 & - \\
Adsorption & $2.3 \pm 0.1$ & $2.1 \pm 0.1$ & $2.2 \pm 0.1$ \\
\hline${ }^{\mathrm{a}}$ Calculated for a $1: 1$ mixture at $328 \mathrm{~K}$ and 1 bar total \\
pressure.
\end{tabular}

In contrast to the gaseous conditions employed in our breakthrough measurements, adsorptive butene isomer separations in the chemical industry would likely be performed at higher pressures with liquefied $\mathrm{C}_{4}$ streams. ${ }^{16}$ To more closely model these conditions, we also performed batch adsorption experiments using solutions containing all three $n$-butene isomers in cyclohexane- $d_{12}(\sim 0.5 \mathrm{M}$ total butenes). Proton NMR spectra were collected for these solutions before and after exposure to $\mathrm{Ni}_{2}(m$-dobdc) at $306 \mathrm{~K}$ for $24 \mathrm{~h}$, and the amount of each adsorbed butene was determined from its concentration difference between the samples. The calculated 1-butene/cis2-butene and 1-butene/trans-2-butene selectivity values determined from these competitive adsorption experiments are listed in Table 3. While the 1-butene/cis-2-butene selectivity is comparable to that determined from single-component isotherms using IAST $(2.3 \pm 0.1$ versus 2.4 , respectively), the 1 butene/trans-2-butene selectivity decreases substantially in the batch adsorption experiment $(2.1 \pm 0.1$ versus 6.0 for IAST). As implicated in the gas-phase breakthrough experiments, the two-component 1-butene/trans-2-butene selectivity is also slightly smaller than that for 1-butene/cis-2-butene. This result suggests that adsorbate-adsorbate interactions are more pronounced between 1-butene and trans-2-butene relative to 1butene and cis-2-butene and ultimately facilitate increased adsorption of trans-2-butene. We note that it is not possible to completely rule out a small amount of cyclohexane- $d_{12}$ adsorption (solution concentration of approximately $9 \mathrm{M}$ ), which could play a minor role in altering selectivity. Nonetheless, the retention of 1-butene selectivity in a mixture containing both olefins and paraffins is significant, given that Raffinate II contains substantial quantities of both $n$-butane and $i$-butane. ${ }^{11}$ In combination with the established performance of the $\mathrm{M}_{2}(\mathrm{~m}$ dobdc) frameworks for separation of light olefin/paraffin mixtures, ${ }^{44}$ these results further attest to the potential of $\mathrm{Ni}_{2}(\mathrm{~m}$ dobdc) to isolate 1-butene from industrially relevant $\mathrm{C}_{4}$ mixtures.

\section{CONCLUSIONS}

The foregoing results show that $\mathrm{Co}_{2}(m$-dobdc $)$ and $\mathrm{Ni}_{2}(m-$ dobdc) are promising materials for the adsorptive separation of $n$-butene isomeric mixtures. Further, this work marks the first example of framework open-metal site selectivity for 1butene over cis-2-butene. This selectivity ultimately enables separation of both 2-butene isomers from 1-butene in a column breakthrough setup, as well as in liquid phase batch adsorption experiments. While the moderate 1-butene selectivities determined here would require use of multiple separation stages to produce high-grade 1-butene from crude industrial $\mathrm{C}_{4}$ streams, the observed electronic structure trends suggest that materials featuring open metal sites with high charge densities are promising targets for this application and warrant continued exploration. For example, the installation of charge-dense open metal sites into molecular sieves that already exhibit selectivity for 1-butene represents an alternative strategy that could offer improvements to established adsorptive separation schemes.

\section{ASSOCIATED CONTENT}

\section{Supporting Information}

The Supporting Information is available free of charge on the ACS Publications website.

Experimental details and supplementary figures and tables (PDF) $\mathrm{X}$-ray crystallographic data for $\mathrm{Co}_{2}$ (dobdc) (1-butene) $)_{1.59}$ (CIF) $\mathrm{X}$-ray crystallographic data for $\mathrm{Co}_{2}$ (dobdc) (cis-2-butene) $)_{1.58}$ (CIF)

X-ray crystallographic data for $\mathrm{Co}_{2}(\text { dobdc)(trans-2-butene })_{1.48}$ (CIF)

X-ray crystallographic data for $\mathrm{Co}_{2}(m$-dobdc $)(1 \text {-butene })_{1.64}$ (CIF) $\mathrm{X}$-ray crystallographic data for $\mathrm{Co}_{2}(m$-dobdc $)(\text { cis-2-butene })_{2.88}$ (CIF)

\section{AUTHOR INFORMATION}

\section{Corresponding Author}

jrlong@berkeley.edu

\section{ORCID}

Brandon R. Barnett: 0000-0002-3113-7347

Julia Oktawiec: 0000-0002-2895-3327

Jeffrey R. Long: 0000-0002-5324-1321 


\section{Present Addresses}

$\dagger$ Department of Chemistry and Chemical Biology, Harvard University, 12 Oxford Street, Cambridge, MA 02138.

\section{Notes}

The authors declare the following competing financial interest(s): J.R.L. has a financial interest in Mosaic Materials, Inc. and Flux Technology, Inc., which are developing metal-organic framework adsorbents and metal-organic framework membranes, respectively, for gas separations. The University of California, Berkeley has filed a provisional patent application on the work reported herein, on which B.R.B. and J.R.L. are listed as inventors.

\section{ACKNOWLEDGMENTS}

This research was funded by the U.S. Department of Energy, Office of Science, Office of Basic Energy Sciences under Award DE-SC0019992. Single crystal X-ray diffraction data were collected at the Advanced Light Source beamline 11.3.1 at Lawrence Berkeley National Laboratory, which is supported by the Director, Office of Science, Office of Basic Energy Sciences of the U.S. Department of Energy under contract no. DE-AC0205CH11231. Powder X-ray diffraction data were collected at Beamline 17-BM-B of the Advanced Photon Source, a U.S. Department of Energy Office of Science User Facility operated by Argonne National Laboratory under Contract No. DE-AC0206CH11357. Nuclear Magnetic Resonance (NMR) spectra were acquired in the UC Berkeley College of Chemistry NMR facility utilizing instrumentation supported in part by the National Institutes of Health (S10OD024998). We thank Henry Jiang and Dr. Benjamin Trump for assistance with powder X-ray diffraction data collection, and Dr. Katie R. Meihaus for editorial assistance.

\section{REFERENCES}

(1) Sholl, D. S.; Lively, R. P. Seven Chemical Separations to Change the World. Nature 2016, 532, 435-437.

(2) Eldridge, R. B. Olefin/Paraffin Separation Technology: a Review. Ind. Eng. Chem. Res. 1993, 32, 2208-2212.

(3) Moulijn, J.A. Chemical Process Technology. John Wiley \& Sons, Inc.; Hoboken, NJ, 2013.

(4) Wang, Y.; Peh, S. B.; Zhao, D. Alternatives to Cryogenic Distillation: Advanced Porous Materials in Adsorptive Light Olefin/Paraffin Separations. Small 2019, 15, 1900058.

(5) Barnett, B. R.; Gonzalez, M. I.; Long, J. R. Recent Progress Towards Light Hydrocarbon Separations Using Metal-Organic Frameworks. Trends Chem. 2019, 1, 159-171.

(6) Herm, Z. R.; Bloch, E. D.; Long, J. R. Hydrocarbon Separations in Metal-Organic Frameworks. Chem. Mater. 2014, 26, 323 338.

(7) Bao, Z.; Chang, G.; Xing, H.; Krishna, R.; Ren, Q.; Chen, B. Potential of Microporous Metal-Organic Frameworks for Separation of Hydrocarbon Mixtures. Energy Environ. Sci. 2016, 9, 3612-3641.

(8) Mukherjee, S.; Desai, A. V.; Ghosh, S. K. Potential of MetalOrganic Frameworks for Adsorptive Separation of Industrially and Environmentally Relevant Liquid Mixtures. Coord. Chem. Rev. 2018, $367,82-126$

(9) Wang, Y.; Zhao, D. Beyond Equilibrium: Metal-Organic Frameworks for Molecular Sieving and Kinetic Gas Separation. Crystal Growth \& Design 2017, 17, 2291-2308.

(10) Lin, R.-B.; Xiang, S.; Xing, H.; Zhou, W.; Chen, B. Exploration of Porous Metal-Organic Frameworks for Gas Separation and Purification. Coord. Chem. Rev. 2019, 378, 87-103.

(11) Schulze, J.; Homann, M. $C_{4}$-Hydrocarbons and Derivatives: Resources, Production, Marketing; Ashworth, M. R. F., Translator; Springer-Verlag: Berlin, 1989.
(12) Bender, M. An Overview of Industrial Processes for the Production of Olefins $-\mathrm{C}_{4}$ Hydrocarbons. ChemBioEng Rev. 2014, 1 , $136-147$.

(13) Wittcoff, H. A.; Reuben, B. G.; Plotkin, J. S. Industrial Organic Chemicals, $2^{\text {nd }}$ ed.; John Wiley and Sons, Inc.: Hoboken, NJ, 2004.

(14) Luciani, L.; Seppälä, J.; Löfgren, B. Poly-1-Butene: Its Preparation, Properties and Challenges. Prog. Polymer Sci. 1988, 13, 3762.

(15) Chatterjee, A. M. Butene Polymers, $2^{\text {nd }}$ ed.; John Wiley \& Sons, Inc.: Hoboken, NJ, USA, 2002; Vol. 77.

(16) Gehre, M.; Guo, Z.; Rothenberg, G.; Tanase, S. Sustainable Separations of $\mathrm{C}_{4}$-Hydrocarbons by Using Microporous Materials. ChemSusChem 2017, 10, 3947-3963.

(17) Li, J.-R.; Kuppler, R. J.; Zhou, H.-C. Selective Gas Adsorption and Separation in Metal-Organic Frameworks. Chem. Soc. Rev. 2009, 38, 1477-1504.

(18) Zeolites in Industrial Separation and Catalysis, $1^{\text {st }}$ ed.; Kulprathipanja, S., Ed.; Wiley, 2010.

(19) Padin, J.; Yang, R. T.; Munson, C. L. New Sorbents for Olefin/Paraffin Separations and Olefin Purification for $\mathrm{C}_{4}$ Hydrocarbons. Ind. Eng. Chem. Res. 1999, 38, 3614-3621.

(20) Takahashi, A.; Yang, R. T.; Munson, C. L.; Chinn, D. $\mathrm{Cu}(\mathrm{I})-\mathrm{Y}$-Zeolite as a Superior Adsorbent for Diene/Olefin Separation. Langmuir 2001, 17, 8405-8413.

(21) Takahashi, A.; Yang, R. T.; Munson, C. L.; Chinn, D. Influence of $\mathrm{Ag}$ Content and $\mathrm{H}_{2} \mathrm{~S}$ Exposure on 1,3-Butadiene/1-Butene Adsorption by $\mathrm{Ag}$ Ion-Exchanged $\mathrm{Y}$-Zeolites $(\mathrm{Ag}-\mathrm{Y})$. Ind. Eng. Chem. Res. 2001, 40, 3979-3988.

(22) Tijsebaert, B.; Varszegi, C.; Gies, H.; Xiao, F.-S.; Bao, X.; Tatsumi, T.; Müller, U.; De Vos, D. Liquid Phase Separation of 1Butene From 2-Butenes on All-Silica Zeolite RUB-41. Chem. Commun. 2008, 255, 2480.

(23) Zhang, Z.; Yang, Q.; Cui, X.; Yang, L.; Bao, Z.; Ren, Q.; Xing, H. Sorting of $\mathrm{C}_{4}$ Olefins with Interpenetrated Hybrid Ultramicroporous Materials by Combining Molecular Recognition and SizeSieving. Angew. Chem. Int. Ed. 2017, 56, 16282-16287.

(24) Liao, P.-Q.; Huang, N.-Y.; Zhang, W.-X.; Zhang, J.-P.; Chen, X.-M. Controlling Guest Conformation for Efficient Purification of Butadiene. Science 2017, 356, 1193-1196.

(25) Liu, H.; He, Y.; Jiao, J.; Bai, D.; Chen, D.-L.; Krishna, R.; Chen, B. A Porous Zirconium-Based Metal-Organic Framework with the Potential for the Separation of Butene Isomers. Chem. Eur. J. 2016, 22, 14988-14997.

(26) Alaerts, L.; Maes, M.; van der Veen, M. A.; Jacobs, P. A.; De Vos, D. E. Metal-Organic Frameworks as High-Potential Adsorbents for Liquid-Phase Separations of Olefins, Alkylnaphthalenes and Dichlorobenzenes. Phys. Chem. Chem. Phys. 2009, 11, 2903.

(27) Hartmann, M.; Kunz, S.; Himsl, D.; Tangermann, O.; Ernst, S.; Wagener, A. Adsorptive Separation of Isobutene and Isobutane on $\mathrm{Cu}_{3}(\mathrm{BTC})_{2}$. Langmuir 2008, 24, 8634-8642.

(28) Cui, J.; Zhang, Z.; Tan, B.; Zhang, Y.; Wang, P.; Cui, X.; Xing, H. Efficient Separation of n-Butene and iso-Butene by Flexible Ultramicroporous Metal-Organic Frameworks with Pocket-Like Cavities. Chem. Asian J. 2019, asia.201900735.

(29) Kishida, K.; Okumura, Y.; Watanabe, Y.; Mukoyoshi, M.; Bracco, S.; Comotti, A.; Sozzani, P.; Horike, S.; Kitagawa, S. Recognition of 1,3-Butadiene by a Porous Coordination Polymer. Angew. Chem. Int. Ed. 2016, 55, 13784-13788.

(30) Luna-Triguero, A.; Vicent-Luna, J. M.; Poursaeidesfahani, A.; Vlugt, T. J. H.; Sánchez-de-Armas, R.; Gómez-Álvarez, P.; Calero, S. Improving Olefin Purification Using Metal Organic Frameworks with Open Metal Sites. ACS Appl. Mater. Interfaces 2018, 10, 1691116917.

(31) Lange, M.; Kobalz, M.; Bergmann, J.; Lässig, D.; Lincke, J.; Möllmer, J.; Möller, A.; Hofmann, J.; Krautscheid, H.; Staudt, R.; Gläser, R. Structural Flexibility of a Copper-Based Metal-Organic Framework: Sorption of $\mathrm{C}_{4}$-Hydrocarbons and in Situ XRD. J. Mater. Chem. A 2014, 2, 8075-8085. 
(32) van den Bergh, J.; Gücüyener, C.; Pidko, E. A.; Hensen, E. J. M.; Gascon, J.; Kapteijn, F. Understanding the Anomalous Alkane Selectivity of ZIF-7 in the Separation of Light Alkane/Alkene Mixtures. Chem. Eur. J. 2011, 17, 8832-8840.

(33) Harlfinger, R.; Hoppach, D.; Quaschik, U.; Quitzsch, K. Adsorption of $\mathrm{C}_{4}$ Hydrocarbons on X-Zeolites Containing $\mathrm{Li}^{+}, \mathrm{Na}^{+}, \mathrm{K}^{+}$, $\mathrm{Rb}^{+}$and $\mathrm{Cs}^{+}$Cations. Zeolites 1983, 3 (2), 123-128.

(34) Tielens, F.; Denayer, J. F. M.; Daems, I.; Baron, G. V.; Mortier, W. J.; Geerlings, P. Adsorption of the Butene Isomers in Faujasite: a Combined Ab-Initio Theoretical and Experimental Study. J. Phys. Chem. B 2003, 107, 11065-11071.

(35) Bloch, E. D.; Murray, L. J.; Queen, W. L.; Chavan, S.; Maximoff, S. N.; Bigi, J. P.; Krishna, R.; Peterson, V. K.; Grandjean, F.; Long, G. J.; Smit, B.; Bordiga, S.; Brown, C. M.; Long, J. R. Selective Binding of $\mathrm{O}_{2}$ over $\mathrm{N}_{2}$ in a Redox-Active Metal-Organic Framework with Open Iron(II) Coordination Sites. J. Am. Chem. Soc. 2011, 133, 14814-14822.

(36) Kim, H.; Jung, Y. Can Metal-Organic Framework Separate 1Butene From Butene Isomers? J. Phys. Chem. Lett. 2014, 5, 440-446.

(37) Bao, Z.; Alnemrat, S.; Yu, L.; Vasiliev, I.; Ren, Q.; Lu, X.; Deng, S. Adsorption of Ethane, Ethylene, Propane, and Propylene on a Magnesium-Based Metal-Organic Framework. Langmuir 2011, 27, 13554-13562.

(38) He, Y.; Krishna, R.; Chen, B. Metal-Organic Frameworks with Potential for Energy-Efficient Adsorptive Separation of Light Hydrocarbons. Energy Environ. Sci. 2012, 5, 9107-9120.

(39) Geier, S. J.; Mason, J. A.; Bloch, E. D.; Queen, W. L.; Hudson, M. R.; Brown, C. M.; Long, J. R. Selective Adsorption of Ethylene Over Ethane and Propylene Over Propane in the Metal-Organic Frameworks $\mathrm{M}_{2}$ (dobdc) $(\mathrm{M}=\mathrm{Mg}, \mathrm{Mn}, \mathrm{Fe}, \mathrm{Co}, \mathrm{Ni}, \mathrm{Zn})$. Chem. Sci. 2013, 4, 2054-2061.

(40) Liao, Y.; Zhang, L.; Weston, M. H.; Morris, W.; Hupp, J. T.; Farha, O. K. Tuning Ethylene Gas Adsorption via Metal Node Modulation: $\mathrm{Cu}-\mathrm{MOF}-74$ for a High Ethylene Deliverable Capacity. Chem. Commun. 2017, 53, 9376-9379.

(41) Mason, J. A.; Veenstra, M.; Long, J. R. Evaluating MetalOrganic Frameworks for Natural Gas Storage. Chem. Sci. 2014, 5, $32-51$.

(42) Bloch, E. D.; Queen, W. L.; Krishna, R.; Zadrozny, J. M.; Brown, C. M.; Long, J. R. Hydrocarbon Separations in a MetalOrganic Framework with Open Iron(II) Coordination Sites. Science 2012, 335, 1606-1610.

(43) Kapelewski, M. T.; Geier, S. J.; Hudson, M. R.; Stück, D.; Mason, J. A.; Nelson, J. N.; Xiao, D. J.; Hulvey, Z.; Gilmour, E.; FitzGerald, S. A.; Head-Gordon, M.; Brown, C. M.; Long, J. R.
$\mathrm{M}_{2}$ (m-dobdc) $(\mathrm{M}=\mathrm{Mg}, \mathrm{Mn}, \mathrm{Fe}, \mathrm{Co}, \mathrm{Ni})$ Metal-Organic Frameworks Exhibiting Increased Charge Density and Enhanced $\mathrm{H}_{2}$ Binding at the Open Metal Sites. J. Am. Chem. Soc. 2014, 136, 12119-12129.

(44) Bachman, J. E.; Kapelewski, M. T.; Reed, D. A.; Gonzalez, M. I.; Long, J. R. $\mathrm{M}_{2}(m$-dobdc) $(\mathrm{M}=\mathrm{Mn}, \mathrm{Fe}, \mathrm{Co}, \mathrm{Ni})$ Metal-Organic Frameworks as Highly Selective, High-Capacity Adsorbents for Olefin/Paraffin Separations. J. Am. Chem. Soc. 2017, 139, 15363-15370.

(45) Gonzalez, M. I.; Kapelewski, M. T.; Bloch, E. D.; Milner, P. J.; Reed, D. A.; Hudson, M. R.; Mason, J. A.; Barin, G.; Brown, C. M.; Long, J. R. Separation of Xylene Isomers Through Multiple Metal Site Interactions in Metal-Organic Frameworks. J. Am. Chem. Soc. 2018, 140, 3412-3422.

(46) Herm, Z.R.; Wiers, B.M.; Mason, J.A.; van Baten, J.M.; Hudson, M.R.; Zajdel, P.; Brown, C.M.; Masciocchi, N.; Krishna, R.; Long, J.R. Separation of Hexane Isomers in a Metal-Organic Framework with Triangular Channels. Science 2013, 340, 960-964.

(47) We note that the derivation of the Clausius-Clapeyron equation does not account for the adsorbed phase volumes, which can lead to artificial correlations between enthalpy and loading. However, any such correlation should be manifested only at very high loadings. See: Pan, H.; Ritter, J. A.; Balbuena, P. B. Examination of the Approximations Used in Determining the Isosteric Heat of Adsorption From the Clausius-Clapeyron Equation. Langmuir 1998, 14, 6323-6327.

(48) Chatt, J.; Duncanson, L. A. Olefin Coordination Compounds. Part III. Infrared Spectra and Structure: Attempted Preparation of Acetylene Complexes. J. Chem. Soc. 1953, 2939-2947.

(49) Myers, A. L.; Prausnitz, J. M. Thermodynamics of MixedGas Adsorption. AIChE J. 1965, 11, 121-127.

(50) Yaghi, O. M.; Kalmutzki, M. J.; Diercks, C. S. Introduction to Reticular Chemistry: Metal-Organic Frameworks and Covalent Organic Frameworks; Wiley-VCH Verlag \& Co. KGaA, 2019.

(51) Queen, W. L.; Hudson, M. R.; Bloch, E. D.; Mason, J. A.; Gonzalez, M. I.; Lee, J. S.; Gygi, D.; Howe, J. D.; Lee, K.; Darwish, T. A.; James, M.; Peterson, V. K.; Teat, S. J.; Smit, B.; Neaton, J. B.; Long, J. R.; Brown, C. M. Comprehensive Study of Carbon Dioxide Adsorption in the Metal-Organic Frameworks $\mathrm{M}_{2}$ (dobdc) $(\mathrm{M}=\mathrm{Mg}$, $\mathrm{Mn}, \mathrm{Fe}, \mathrm{Co}, \mathrm{Ni}, \mathrm{Cu}, \mathrm{Zn})$. Chem. Sci. 2014, 5, 4569-4581.

(52) Peralta, D.; Chaplais, G.; Simon-Masseron, A.; Barthelet, K.; Pirngruber, G. D. Separation of $\mathrm{C}_{6}$ Paraffins Using Zeolitic Imidazolate Frameworks: Comparison with Zeolite 5A. Ind. Eng. Chem. Res. 2012, 51, 4692-4702. 


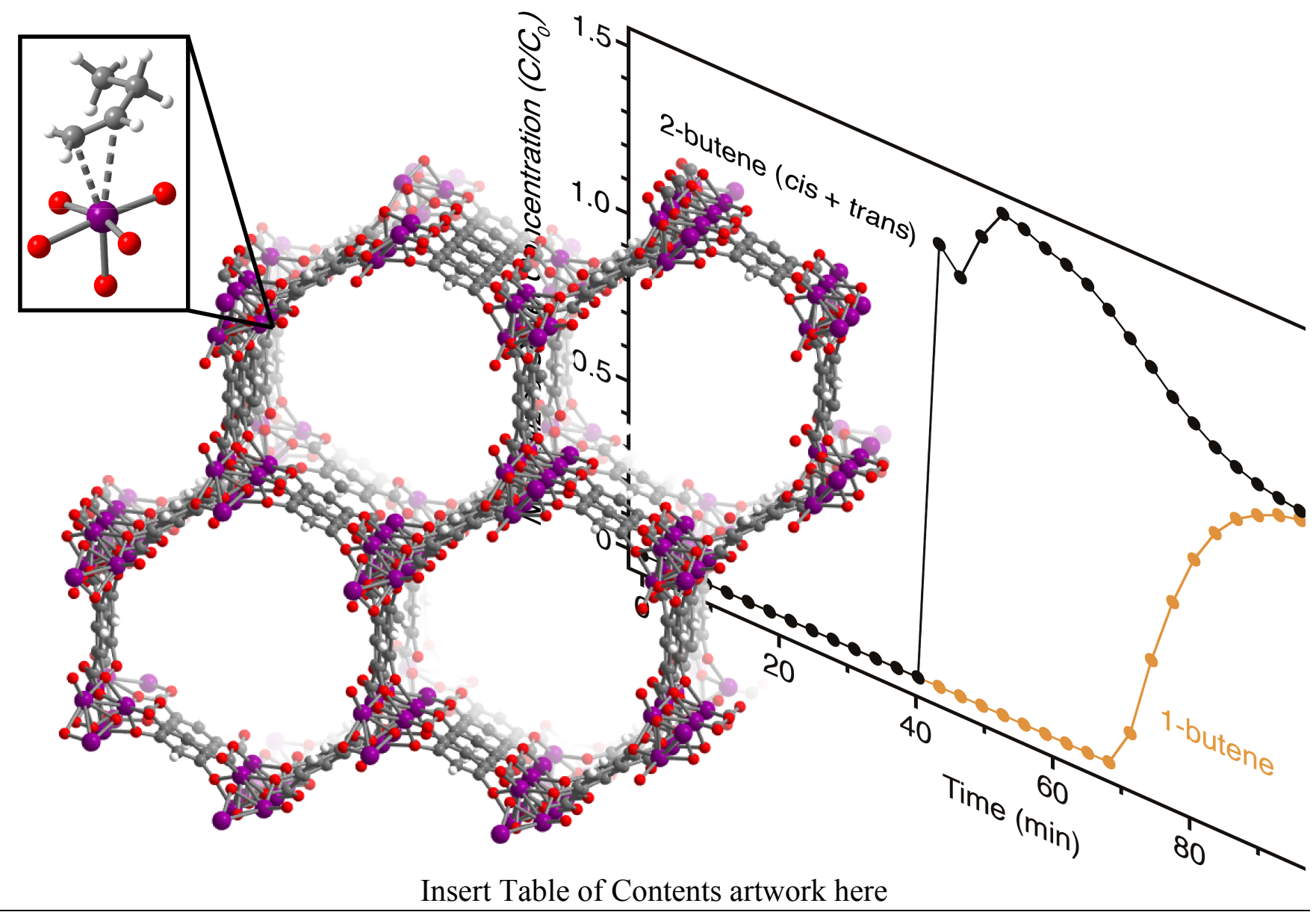

